\title{
Inhibition of livin gene combined with cisplatin affect the apoptosis of laryngeal carcinoma Hep-2 cells by RNA interference technique
}

\author{
Wang $\mathrm{SL}^{1 *}$, Deng $\mathrm{WT}^{1}$, Wen $\mathrm{GF}^{1}$ and Zeng $\mathrm{YJ}^{2}$ \\ ${ }^{1}$ Department of Otorhinolaryngology Head and Neck Surgery, Shantou City Central Hospital, China \\ ${ }^{2}$ Beijing University of Technology, Biomedical Engineering Center, China
}

\begin{abstract}
Objective: To explore cisplatin-induced apoptosis and proliferation inhibition effect of Hep-2 cells following the interference of livin expression in laryngeal carcinoma, and to explore the mechanism of livin in the drug resistance of laryngeal carcinoma cell line Hep-2.

Methods: Different concentrations of cisplatin were acted on laryngeal carcinoma Hep-2 cells. The MTT assay was used to detect changes of laryngeal carcinoma cells on the proliferation inhibitory sensitivity of cisplatin following the exhibition of livin expression. The apoptosis rate was detected after laryngeal carcinoma cell line was treated by cisplatin for $48 \mathrm{~h}$, and the change of apoptotic factor capase- 3 activity was detected.

Results: $1 . \mathrm{MTT}$ assay results showed that by interfering livin gene expression, at the same cisplatin concentrations, the proliferation inhibition rate of cells in the group Hep2-pLivin was significantly higher than that of the Hep2-pHK $(P<0.05) 2$. After inhibiting the expression of livin gene in laryngeal carcinoma cells, the activity of caspase- 3 in cells might be enhanced, and the activation effect was further enhanced after the addition of cisplatin.
\end{abstract}

Conclusion: Targeting inhibition of the expression of livin gene can enhance the apoptosis of laryngeal carcinoma cells and improve the sensitivity to cisplatin.

\section{Introduction}

Cisplatin(DDP)-based combined chemotherapy regimen is an important method for the treatment of laryngeal carcinoma. New treatment regimens, taking the preservation of laryngeal function as object, plus chemotherapy (predominant by cisplatin and 5-fluorouracil) on the basis of the application of radical radiotherapy, can significantly improve the survival rate of $5 \%$ to $10 \%$ than radiotherapy alone [1].

Overexpression of inhibitor of apoptosis protein is one of the important reasons for the failure of chemotherapy in tumor cells, and the apoptosis of the cells can be induced by decreasing the activity of the inhibitor of apoptosis protein [2]. Livin, as a newly discovered inhibitor of apoptosis protein, is selectively highly expressed in most common human cancer, which closely related to the occurrence and development of tumor and drug resistance [3]. The fact that laryngeal carcinoma cells is not sensitive to cisplatin treatment and high expression of livin has been found in the cell suggested that livin induced apoptosis inhibition may be strongly correlated with the drug resistance of laryngeal carcinoma. Besides, there was previous research livin gene silencing can inhibit the invasion of laryngeal cancer cell [4].

To explore the possibility and preliminary mechanism of the silencing of livin gene combined with cisplatin in increasing the curative effect of laryngeal carcinoma, in the preparatory experiment, Hep- 2 cells has been successfully screened via silencing the expression of livin gene using valid sequences of shRNA in vitro (5), and taking it as the research object, in the present study, $5 \mu \mathrm{g} / \mathrm{ml}$ dose of cisplatin targeting Hep-2 cells in shRNA silencing of livin gene were observed to explore cisplatin-induced apoptosis and proliferation inhibition effect of Hep-2 cells following the interference of livin expression in laryngeal carcinoma (Figure 1).

\section{Materials and methods}

\section{Materials}

Escherichia coli DH5 $\alpha$ and plasmid pGenesil-1 were purchased from Wuhan Genesil Biotechnology Co. Ltd.; oligonucleotides, primers, liposome Lipofectamine 2000 and Opti-MEM1 serumfree medium were purchased from Invitrogen company (America); restriction endonuclease, including SalI and BamHI, as well as HindIII T4 ligase, and small Plasmid Extraction Kit, real-time quantitative PCR kit were purchased from Dalian Takara company; mouse anti-human livin monoclonal antibody, Rabbit anti-human $\beta$-actin monoclonal antibody and Rabbit anti-rat livin labeled secondary antibody, as well as the Western blot were purchased from Wuhan boster company; cisplatin was purchased from Shandong Qilu pharmaceutical; MTT was purchased from Sigma Co. Ltd. (America); Apoptosis kit and Caspase-3 spectrophotometry assay kit were purchased from Nanjing KeyGen BioTech Co. Ltd..

${ }^{*}$ Correspondence to: Wang SL, Department of Otorhinolaryngology Head and Neck Surgery, Shantou City Central Hospital, Shantou, China, Tel: +86 7548855 0450; E-mail: shuangle999@163.com

Key words: livin, cisplatin, RNA interference, Hep-2 cell, apoptosis

Received: June 07, 2018; Accepted: June 22, 2018; Published: June 27, 2018 


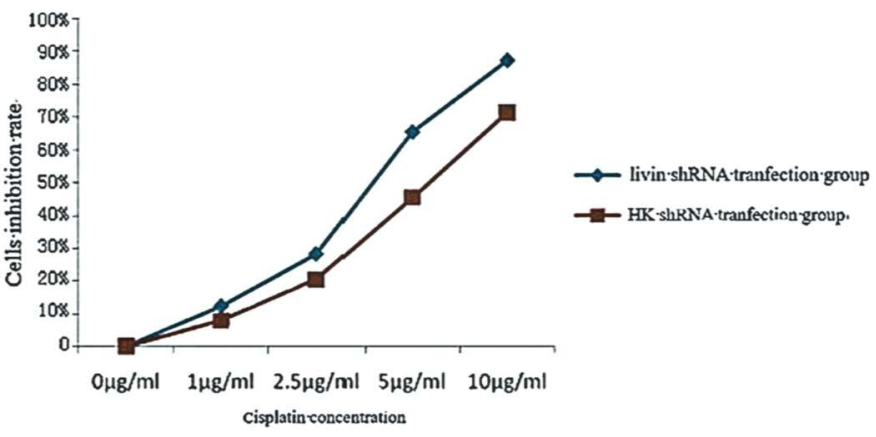

Figure 1. Silencing the livin gene inhibits the sensitivity of Hep-2 cells to cisplatin

\section{Methods}

\section{shRNA sequence design and construction of recombinant}

According to the cDNA sequence of Livin gene reported in Genebank (No.NM022161, No.NM139317), and in accordance with the design principles of shRNA, the design of livin interference sequence in the application of RNA interference software was inserted into the pGenesil plasmid. The positive plasmid was named pGenesil-Livin, and the unrelated negative plasmid was named pGenesil-HK.

\section{Hep-2 cell culture and stable transfection of interfering} plasmid in laryngeal carcinoma

Hep-2 cells were cultured with DMEM medium containing $10 \%$ fetal bovine serum at $37^{\circ} \mathrm{C}$ and $5 \% \mathrm{CO}_{2}$. The transfection process was carried out according to the specification of Lipofectamine 2000. With a concentration of $500 \mu \mathrm{g} / \mathrm{ml} \mathrm{G} 418$ for resistance screening to obtain a stable expression of cell lines, the positive plasmid was named as Hep2pLivin, and the negative control plasmid of the monoclonal cells was named as Hep2-pHK.

The effect of cisplatin following siRNA interfered livin gene on the proliferation inhibitory sensitivity of laryngeal cancer cells after interference gene detected by the MTT colorimetric method

Hep2-pLivin and Hep2-pHK cells were cultured on 96-well plates with approximately 4500 cells per hole. The culture medium was replaced 24 hours later, cisplatin was further added to the final concentration of $1 \mu \mathrm{g} / \mathrm{ml}, 2.5 \mu \mathrm{g} / \mathrm{ml}, 5 \mu \mathrm{g} / \mathrm{ml}$, and $10 \mu \mathrm{g} / \mathrm{ml}$, respectively. To $48 \mathrm{~h}, 20 \mu \mathrm{l}$ MTT $(5 \mathrm{mg} / \mathrm{ml})$ were added to each hole, and then incubated at $37^{\circ} \mathrm{C}$ for $4 \mathrm{~h}$ without lighting. Subsequently, medium and MTT were carefully absorbed, and 100ul DMSO were added per hole, shook at the shelter for 10 min without the light. Negative control did not add cisplatin; equal amounts of medium were added in the blank control group without cells. The absorbance value (OD) of each hole was measured by the $570 \mathrm{~nm}$ wavelength of the enzyme marker. The calculation was repeated for 3 times, 5 replicates were made for each time. Cell inhibition rate $=1-(\mathrm{OD}$ value of the drug treatment group - OD value of the blank control group)/(OD value of the cell control group - OD value of the blank control group $] \times 100 \%$.

The effect of cisplatin following siRNA interfered livin gene on the apoptosis sensitivity of laryngeal cancer cells after interference gene detected by flow cytometry

Hep2-pHK and Hep2-pLivin cells were cultured with DMEM medium containing $5 \mu \mathrm{g} / \mathrm{ml}$ cisplatin, and 48 hours later, the culture medium was discarded, digestion was further conducted with trypsin not containing ETDA, followed by suspension cell centrifugation at 2000rpm for $5 \mathrm{~min}$. And then, washing cells with PBS for two times (2000 rpm, $5 \mathrm{~min}$ ) to collect cells at a density of $1-5 \times 10^{5}$. A $500 \mu \mathrm{L}$ buffer binding suspension was added to suspend cells. Subsequently, $5 \mu \mathrm{L}$ Annexin V-APC was added and well mixed, following an adding of $5 \mu \mathrm{L}$ PI dyeing solution and mixed, reacted at room temperature for $5 \sim 15 \mathrm{~min}$ avoiding lighting. Flow cytometry was further performed within $1 \mathrm{~h}$ (Figure 2).

Detection of siRNA interference livin gene after cisplatin induced changes in the activity of Caspase- 3 in laryngeal cancer cells

(1) Hep2-pLivin and pHK Hep2- cells were cultured by DMEM culture medium containing $5 \mu \mathrm{g} / \mathrm{ml}$ for $48 \mathrm{~h}$, and then the culture medium was discarded, the cells were collected, and the total protein was extracted. Determination of protein concentration was conducted by BCA. A $50 \mu \mathrm{L}$ cell lysis supernatant containing $100 \mu \mathrm{g}$ protein was absorbed, and a $50 \mu \mathrm{L}$ reaction buffer was added. And then, $5 \mu \mathrm{L}$ caspase- 3 substrates was added and incubated at $37 \nabla$ for $4 \mathrm{~h}$ to avoid light, enzyme labeled instrument at $405 \mathrm{~nm}$ was selected for the determination of the light absorption value, caspase- 3 activation in apoptosis induced group was determined by calculating the ratio of OD value of the inducer/the OD value of the negative control group, HK shRNA without cisplatin was considered as the negative control group.

\section{Statistical analysis}

Average values were taken from the result of multiple tests. Statistical analysis was performed with SPSS 16 software. Single factor analysis of variance was used to compare the differences of average data among multiple groups. $P<0.05$ is considered to have statistical significance.

\section{Results}

Effect of siRNA interfered livin gene on the proliferation inhibitory sensitivity of laryngeal cancer cells induced by cisplatin

MTT colorimetric detection obtained cell proliferation curves as below. At the same cisplatin concentrations, the proliferation inhibition rate of cells in the group Hep2-pLivin was significantly higher than that of the Hep2-pHK $(P<0.05)$ and inhibit effect gradually increased following increased concentration of cisplatin. This result indicated that by interfering with the expression of livin gene, the antitumor activity of cisplatin might be enhanced and showed a concentration dependent, under the action of $10 \mu \mathrm{g} / \mathrm{ml}$ cisplatin for $48 \mathrm{~h}$, the proliferation inhibitory rate of cells in the Hep2-pLivin group and the Hep2-pHK was $87.26 \%$ and $71.38 \%$, respectively.

\section{Effect of siRNA interfered livin gene on apoptosis sensitivity of laryngeal cancer cells induced by cisplatin}

Flow cytometry detection results showed that plus the treatment regimen of $5 \mu \mathrm{g} / \mathrm{ml}$ cisplatin to HEp-2 cells for $48 \mathrm{~h}$, cell apoptosis rate in the livin shRNA transfection + cisplatin group $(24.93 \pm 0.27)$, livin shRNA transfection group $(12.27 \pm 0.47)$, HK shRNA transfection + cisplatin group $(12.00 \pm 0.61)$ were significantly higher than that of HK shRNA transfection group $(4.22 \pm 0.23)(P<0.05)$. Besides, rate of apoptosis in the livin shRNA transfection + cisplatin group was significantly higher than that of livin shRNA transfection group and HK shRNA transfection + cisplatin group; whereas the apoptosis rate in the HK shRNA transfection+ cisplatin group and livin shRNA transfection group showed no significant difference $(P=0.288>0.05)$. In 

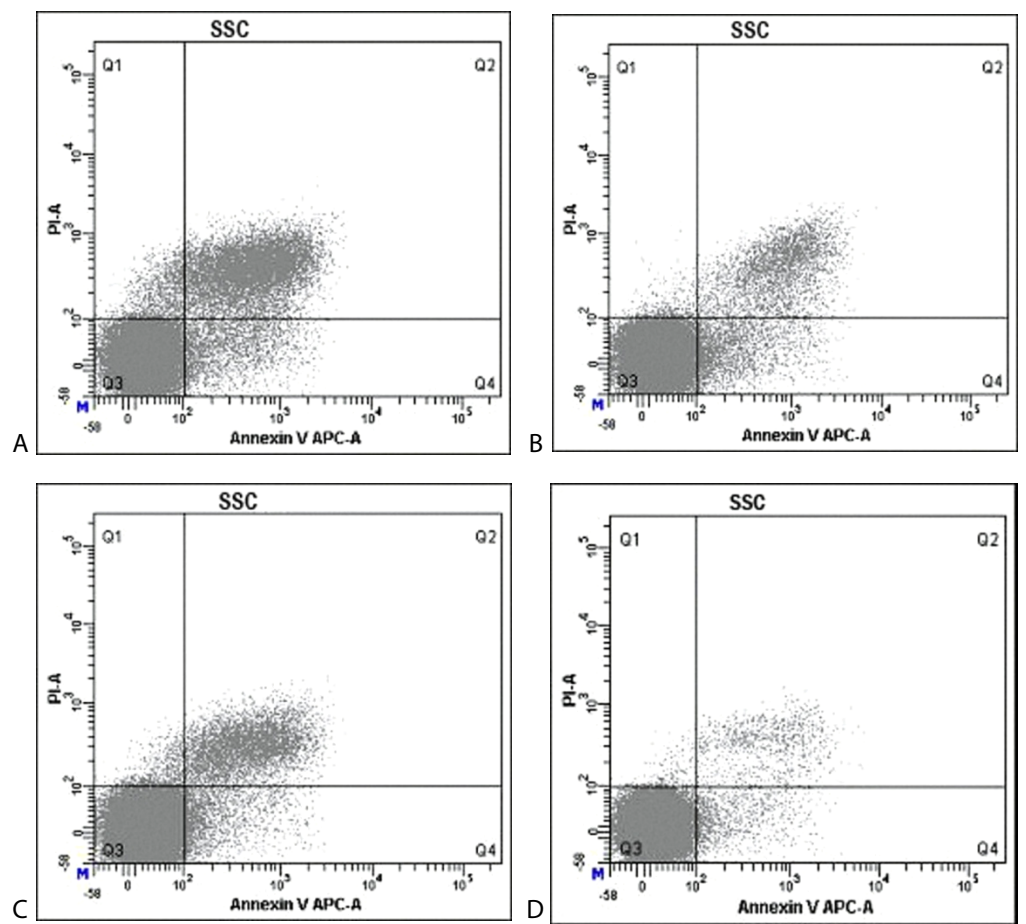

Figure 2. Annexin V-APC/PI double staining method detected the effect of livin gene silencing on the apoptotic sensitivity of HEp-2 cells induced by cisplatin. A: livin shRNA transfection + cisplatin group; B: HK shRNA + cisplatin group; C: livin shRNA transfection group; D: HK shRNA transfection group

addition, cells apoptosis rate in the livin shRNA transfection group was significantly higher than that of negative HK shRNA transfection group $(P<0.05)$.

\section{SiRNA interference of livin gene after cisplatin induced changes in the activity of Caspase- 3 in laryngeal cancer cells}

Spectrophotometric detection results showed as below: compared with negative control shRNA HK transfection group, caspase-3 activities were significantly increased in the livin shRNA transfection+ cisplatin group $(2.88 \pm 0.07)$, livin shRNA transfection group $(1.91$ $\pm 0.05)$, and HK shRNA transfection + cisplatin group $(1.90 \pm 0.03)$ $(P<0.05)$, among which caspase- 3 activities were obviously higher in the livin shRNA transfection+ cisplatin group than that of livin shRNA transfection group, and HK shRNA transfection + cisplatin group $(P<0.05)$, while there was no apparent statistical significance regarding caspase- 3 activity between livin shRNA transfection group and HK shRNA transfection+ cisplatin group $(\mathrm{P}=0.677>0.05)$. Above results suggested that following the in vitro inhibition of the livin gene, the activity of caspase- 3 in laryngeal cancer cells increased after the addition of cisplatin, and the degree of activation was further improved.

\section{Discussion}

Chemotherapy is one of the important ways to treat cancer. Activation of caspase family protease is the key mechanism to promote apoptosis of tumor cells induced by chemotherapeutic drugs. Therefore, the main reason of drug resistance is the deficiency or inhibition of caspase activity in tumor cells [6].

Caspases protein is an important family protein that mediates cells apoptosis. Most of the apoptotic stimulus are caused by the cascade reaction of caspase protein, which cause cells apoptosis $[7,8]$.

Laryngeal carcinoma is a common malignant tumor of the head and neck, induction chemotherapy, cycle chemotherapy and palliative chemotherapy treatment can obtain certain curative effect on the basis of cisplatin scheme in laryngeal cancer, how to improve the cisplatin sensitivity of tumor cells is one of the research hotspots [9]. Studies have shown that cisplatin can induce the apoptosis of renal cells by the increased intracellular P53 mediated caspase-3 activity [10]. P-glycoprotein can reduce the sensitivity of L1210 cells to cisplatin by inhibiting the activity of caspase-3 [11], which indicates that cell apoptosis induced by cisplatin has a close relationship with caspase- 3 .

Livin is a new member of the inhibitor of apoptosis protein (IAP), which is low or no expressed in most normal adult tissues but is highly expressed in many malignant tumors. Livin contains IAP protein specific BIR and RING domain, BIR mediated livin binds with Caspase- 3 and leads to inactivation and degradation of Caspases-3 protein. Some studies suggested that livin has the function that ubiquitin ligase (U biquitin ligase, E3) possessed [12], leading to ubiquitination of the target protein, caspases, and then degraded by hydrolyzed protein complexes, resulting in the inhibition of cells apoptosis. Livin can also inhibit the function of IAPs by combining and neutralizing with SMAC, to inhibit caspase-3, thereby playing a role in inhibiting apoptosis [13]. SiRNA interference of livin gene expression can lead to increased activity of caspase-3, caspase-3 is the main protein to induce cells apoptosis [14], suggesting that livin is an inhibitor of caspase-3.

Studies have shown that the high expression of livin plays a key role in the tolerance of tumor cells to chemotherapy and radiotherapy induced apoptosis. Zhang et al. [15], found that in the use of anticancer drugs in the treatment of leukemia, livin protein expression affected cancer cell resistance to chemotherapeutic drugs, the higher livin protein expression, the higher drug resistance of cancer cells. Liu et al. [3], also showed that inhibiting the expression of livin can improve the sensitivity of HepG2 cells to chemotherapeutic drugs.

RNA interference is a kind of independent RNA producing process of silence. A number of studies have shown that livin gene expression 
can increase the sensitivity of tumor cells to chemotherapeutic drugs by RNAi technology. Yu et al. [16], observed that pshRNA-Livin inhibited the expression of livin gene in cervical cancer by shRAN technology, promoting apoptosis of tumor cells, inhibiting the growth of tumor, and hence enhancing the role of apoptosis induced by cisplatin; apoptosis related gene bcl-2 expression level was shown to be decreased in the apoptotic process, whereas expression levels of survivin, Bax, caspase-3 were increased. We designed to provide experimental evidence for the clinical application of RNAi and livin as the target for chemotherapy sensitivity therapy for tumors. siRNA mediated expression of livin can significantly inhibit the proliferation ability of bladder cancer T24 cells, reduced the expression of livin can increase the rate of T24 cell to the apoptosis rates of mitomycin C and TNF-a, and correlated with the increased activities of caspase- 3 and caspase-9 [17]. And the correlation between the effect of chemotherapy and livin expression is not yet reported in laryngeal cancer.

In this experiment, we chose cisplatin as apoptosis stimulating factor to observe the effect of livin gene silencing on chemotherapeutic sensitivity of laryngeal carcinoma cell line. Plasmids were transfected into positive plasmid of livin shRNA and negative plasmid of HK shRNA cells for $48 \mathrm{~h}$ under the action of the same concentration of cisplatin and found that the inhibition rate of livin shRNA transfected cells was significantly higher than that of HK shRNA transfected cells, and inhibition rate increased following the elevated cisplatin concentration. By interfering with the expression of livin gene, the inhibition effect of cisplatin on laryngeal carcinoma cells was enhanced, and the antitumor activity was greatly increased (Figure 3 ).

The apoptosis rate of cells apoptosis was detected by flow cytometry in Hep-2 cells adding $5 \mu \mathrm{g} / \mathrm{ml}$ of cisplatin for $48 \mathrm{~h}$. The analysis results showed that the SiRNA silencing livin gene expression could significantly increase the sensitivity of HEp-2 cells to cisplatin induced apoptosis.

Relationship between tumor cells apoptosis inhibition and resistance to chemotherapy has been hotspot in gene research $[18,19]$. In this study, to further explore the molecular mechanism of livin gene silencing increased HEp-2 cells to cisplatin induced apoptosis sensitivity, spectrophotometric detection was applied and showed that following the inhibition of livin gene in cells, enhanced activity of caspase- 3 was found in human laryngeal carcinoma cells, and the level of activation was further strengthened after the addition of cisplatin. Present analysis showed that after siRNA silencing of livin gene, downregulation of the expression of livin was detected, lifting the inhibition of caspase- 3 , thereby caspase- 3 was activated which in turn sequentially activated the other members of the caspase family, formed the caspase

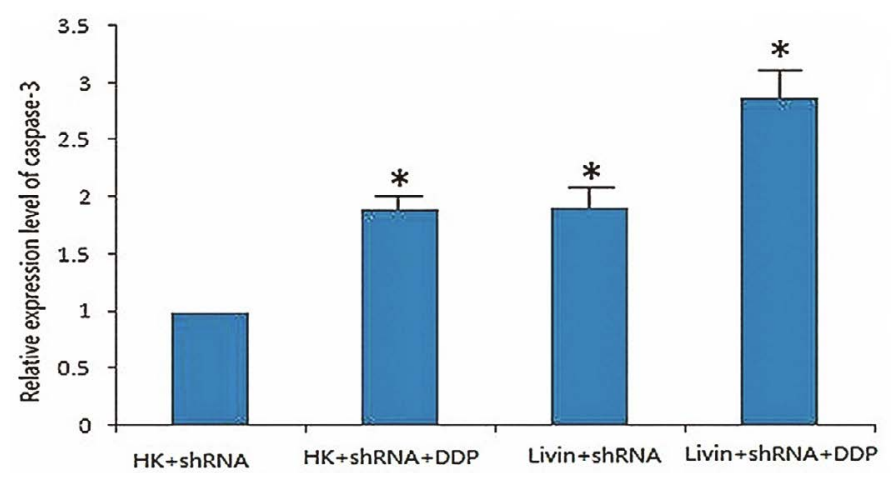

Figure 3. Effect of livin gene silencing on the relative activity of Hep-2 in caspase-3 cells induced by cisplatin cascade, eventually lifting the apoptosis inhibition of Hep-2 cell to increase the sensitivity of HEp-2 cells to cisplatin induced apoptosis. This study further confirmed that apoptosis inhibition is an important cause of tumor resistance to chemotherapy.

\section{Conclusion}

Targeting inhibition of the expression of livin gene by RNAi technology can inhibit the proliferation of laryngeal squamous cell carcinoma and improve the sensitivity of cisplatin induced apoptosis in HEp-2 cell. This may provide new ideas for the clinical treatment of laryngeal carcinoma, and livin may is a new target for gene therapy of laryngeal carcinoma, downregulation of livin expression can improve the sensitivity of chemotherapy and contribute greatly to the preservation of laryngeal function in laryngeal carcinoma patients.

\section{References}

1. Choong N, Vokes E (2008) Expanding role of the medical oncologist in the management of head and neck cancer. CA Cancer J Clin 58: 32-53. [Crossref]

2. Iovine B, Guardia F, Irace C, Bevilacqua MA (2016) 1-carnosine dipeptide overcomes acquired resistance to 5-fluorouracil in HT29 human colon cancer cells via downregulation of HIF1-alpha and induction of apoptosis. Biochimie 127: 196-204. [Crossref]

3. Liu F, Chang H, Xu W, Zhai Y (2015) The effects of Livin shRNA on the response to cisplatin in HepG2 cells. Oncol Lett 10: 2957-2961. [Crossref]

4. Yoon TM, Kim SA, Lee DH, Lee JK, Park YL, et al. (2014) Expression of Livin and the inhibition of tumor progression by Livin silencing in laryngohypopharyngeal cancer. In Vivo 28: 751-759. [Crossref]

5. Wang SL, Deng WT, Wen GF, Li CW, Zeng YJ (2016) Construction of a Hep-2 cell line stably transfected with Livin shRNA. Bratisl Lek Listy 117: 272-275. [Crossref]

6. Brumatti G, Ma C, Lalaoui N, Nguyen NY, Navarro M, Tanzer MC, et al. (2016) The caspase-8 inhibitor emricasan combines with the SMAC mimetic birinapant to induce necroptosis and treat acute myeloid leukemia. Sci Transl Med 8: 339-369.

7. Shiozaki EN, Shi Y (2004) Caspases, IAPs and Smac/DIABLO: mechanisms from structural biology. Trends Biochem Sci 29: 486-494. [Crossref]

8. Riedl SJ, Shi Y (2004) Molecular mechanisms of caspase regulation during apoptosis. Nat Rev Mol Cell Biol 5: 897-907. [Crossref]

9. Lv X, Song DM, Niu YH, Wang BS (2016) Inhibition of heme oxygenase-1 enhances the chemosensitivity of laryngeal squamous cell cancer Hep-2 cells to cisplatin. Apoptosis 21: 489-501. [Crossref]

10. Cummings BS, Schnellmann RG (2002) Cisplatin-induced renal cell apoptosis: caspase 3-dependent and -independent pathways. J Pharmacol Exp Ther 302: 8-17. [Crossref]

11. Gibalova L, Seres M, Rusnak A, Ditte P, Labudova M, et al. (2012) P-glycoprotein depresses cisplatin sensitivity in L1210 cells by inhibiting cisplatin-induced caspase-3 activation. Toxicol In Vitro 26: 435-444. [Crossref]

12. Vaux DL, Silke J (2005) IAPs, RINGs and ubiquitylation. Nat Rev Mol Cell Biol 6 287-297. [Crossref]

13. Vucic D, Deshayes K, Ackerly H, Pisabarro MT, Kadkhodayan S, et al. (2002) SMAC negatively regulates the anti-apoptotic activity of melanoma inhibitor of apoptosis (ML-IAP). J Biol Chem 277: 12275-12279. [Crossref]

14. Mazumder S, Plesca D, Almasan A (2008) Caspase-3 activation is a critical determinant of genotoxic stress-induced apoptosis. Methods Mol Biol 41: 13-21. [Crossref]

15. Zhang QP, Xiong J, Jin YX, Wei J, Chun L, et al. (2004) CC chemokine ligand 25 enhances resistance to apoptosis in CD4 + T cells from patients with T2cell lineageacute and chronic lymphocytic leukemia bymeans of livin activation. Cancer Res 64: 75797587. [Crossref]

16. Yu L, Wang Z (2009) Effects of Livin gene RNA interference on apoptosis of cervical cancer HeLa cells and enhanced sensitivity to cisplatin. J Huazhong Univ Sci Technolog Med Sci 29: 625-630. [Crossref]

17. Yang DY, Song XS, Zhang JN, Ye L, Wang S, et al. (2010) Suppression of livin gene expression by siRNA leads to growth inhibition and apoptosis induction in human bladder cancer T24 cells. Biosic Biotechnol Bioc 74: 1039-1044. [Crossref] 
Wang SL (2018) Inhibition of livin gene combined with cisplatin affect the apoptosis of laryngeal carcinoma Hep-2 cells by RNA interference technique

18. Zou H, Li L, Garcia Carcedo I, Xu ZP, Monteiro M, et al. (2016) Synergistic inhibition of colon cancer cell growth with nanoemulsion-loaded paclitaxel and PI3K/mTOR dual inhibitor BEZ235 through apoptosis. Int J Nanomedicine 11: 1947-1958. [Crossref]
19. Krumm A, Barckhausen C, Kucuk P, Tomaszowski KH, Loquai C, et al. (2016) Enhanced Histone Deacetylase Activity in Malignant Melanoma Provokes RAD51 and FANCD2-Triggered DrugResistance. Cancer Res 76: 3067-3077. [Crossref]

Copyright: $\odot 2018$ Wang SL. This is an open-access article distributed under the terms of the Creative Commons Attribution License, which permits unrestricted use, distribution, and reproduction in any medium, provided the original author and source are credited. 